\title{
Atık Su Örneklerinde Bazı Ağır Metallerin İndüktif Eşleşmiş Plazma Kütle Spektrometresi (ICP-MS) ile Belirlenmesi
}

\author{
Zekeriyya BAHADIR \\ Giresun Üniversitesi, Fen Edebiyat Fakültesi, Kimya Bölümü, 28100, Giresun, Türkiye
}

Atıf yapmak için: Bahadır, Z. (2020). Atık su örneklerinde bazı ağır metallerin indüktif eşleşmiş plazma kütle spektrometresi (ICP-MS) ile belirlenmesi. Anadolu Çev. ve Hay. Dergisi, 5(1), 56-60.

How to cite: Bahadır, Z. (2020). Determination of some heavy metals in waste water samples with inductively coupled plasma mass spectrometry (ICP-MS). J. Anatolian Env. and Anim. Sciences, 5(1), 56-60.

: https://orcid.org/0000-0002-7035-1258

*Sorumlu yazarm:

Zekeriyya BAHADIR

Giresun Üniversitesi, Fen Edebiyat Fakültesi,

Kimya Bölümü, 28100, Giresun, Türkiye

凶: zekeriyya.bahadir@giresun.edu.tr

Cep telefonu : $+90(553) 4479358$
Öz: Bu çalışmada Giresun ilinde farklı oto yıkama merkezlerinin atık su içeriğindeki Cd, As, $\mathrm{Pb}$, Ni ve $\mathrm{Cr}$ metalleri indüktif eşleşmiş plazma kütle spektrometresi (ICP-MS) ile tayin edilmiştir. $\mathrm{Bu}$ amaçla, belirlenen istasyonlardan toplanan su numuneleri, $0,45 \mu \mathrm{m}$ membran filtreden süzülmüş ve tayin öncesinde asitlendirilerek metal içerikleri analiz edilmiştir. Analiz edilen atık su numuneleri için en yüksek metal konsantrasyonları; As $\left(15,2 \pm 0,3 \mu \mathrm{g} \mathrm{L}^{-1}\right), \mathrm{Pb}$ $\left(26,9 \pm 0,4 \mu \mathrm{g} \mathrm{L}^{-1}\right)$, Ni $\left(31,5 \pm 1,1 \mu \mathrm{g} \mathrm{L}^{-1}\right)$ ve $\mathrm{Cr}\left(9,8 \pm 0,4 \mu \mathrm{g} \mathrm{L}^{-1}\right)$ olarak tespit edilmiştir. Ölçümlerin doğruluğu, numune matriksine ekleme/geri kazanım yöntemi kullanılarak belirlenmiştir. Elde edilen geri kazanım değerleri \%88-108 arasında bulunmuştur. İstasyonlar arası metal konsantrasyonları farklılı̆̆ istatistiksel olarak incelenmiştir.

\section{Anahtar kelimeler: Ağır metal, atık su, ICP-MS.}

\section{Determination of Some Heavy metals in Waste Water Samples with Inductively Coupled Plasma Mass Spectrometry (ICP-MS)}

*Corresponding author's:

Zekeriyya BAHADIR

Giresun University, Department of

Chemistry, Faculty of Arts and Sciences,

28100, Giresun, Turkey

凶: zekeriyya.bahadir@giresun.edu.tr

Mobile telephone : $+90(553) 4479358$

\begin{abstract}
In this study, $\mathrm{Cd}, \mathrm{As}, \mathrm{Pb}, \mathrm{Ni}$ and $\mathrm{Cr}$ metals in waste water content of different car wash centers in Giresun province were determined by inductively coupled plasma mass spectrometry (ICP-MS) technique. For this purpose, the water samples collected from the stations were filtered through a $0.45 \mu \mathrm{m}$ membrane filter and acidified before the determination of the metal contents. The highest metal concentrations were determined for As $(15.2 \pm 0.3 \mu \mathrm{g}$ $\left.\mathrm{L}^{-1}\right), \mathrm{Pb}\left(26.9 \pm 0.4 \mu \mathrm{g} \mathrm{L}^{-1}\right), \mathrm{Ni}(31.5 \pm 1.1 \mu \mathrm{g} \mathrm{L}-1)$ and $\mathrm{Cr}\left(9.8 \pm 0.4 \mu \mathrm{g} \mathrm{L}^{-1}\right)$. The accuracy of the measurements was checked using the addition/recovery method. The recovery values obtained between $88-108 \%$. The difference of metal concentrations between stations was statistically studied.
\end{abstract}

Keywords: Heavy metals, ICP-MS, waste water.

\section{GİRiş}

Son y1llarda teknoloji ve sanayinin hizla gelişmesine bağlı olarak artan çevre kirliliği, insan sağlığını olumsuz yönde etkileyen en önemli sorunlardan biri olarak güncelliğini korumaktadır. Çevre kirliliğinin ana nedenleri arasında ağır metal kirliliği gelmektedir. Ağır metal, nispeten yüksek bir yoğunluğa $\left(5 \mathrm{~g} / \mathrm{cm}^{3}\right.$ den büyük) sahip olan ve düşük konsantrasyonlarda dahi toksik etki gösterebilen metal veya metaloid grubu için kullanılan bir terimdir (Duffus, 2002). Civa, kadmiyum, arsenik, krom, demir, kurşun, çinko, gümüş ve bakır ağır metallere örnek olarak gösterilebilir (Duruibe vd., 2007). Klor bazlı organik kirleticilerin aksine, ağır metaller yer kabuğunda doğal olarak bulunan elementlerdir. İnsani faliyetler sonucu doğada biriken çoğu ağır metal miktarı, doğal kökenli kaynaklardan salınan ağır metal miktarlarına oranla çok daha fazladır. Ağır metaller farklı kimyasal ve fiziksel 
özelliklerinden dolayı, endüstriyel uygulamalarda yaygın olarak kullanılırlar. Metalurji, yakma prosesleri (kömür ve petrol) ve madencilik en önemli ağır metal kaynaklarıdır (Akieh vd., 2008; Jahromi vd., 2007). Ağır metaller biyobozunur özelliğe sahip olmayıp, insan vücuduna yiyecekler, içme suyu ve hava yoluyla alınırlar. Bakır ve çinko gibi bazı ağır metaller düşük konsantrasyonlarda insan metabolizması için gerekli olmalarına rağmen, yüksek miktarda alındıklarında zehirlenmelere neden olabilirler (Vinodh vd., 2011).

Yoğun trafik, endüstriyel faliyetler ve kentleşme; göl, nehir, deniz ve içme sularının ağır metaller tarafından kirletilmesine neden olmakta ve bu durum insan sağlığı için önemli bir sorun teşkil etmektedir (Khajeh vd., 2017). Bu nedenle gerek doğal su gerekse atık su numunelerinde ağır metal konsantrasyonlarının belirlenmesi kirlilik oranın tespiti açısından büyük önem taşımaktadır.

İndüktif eşleşmiş plazma-kütle spektrometresi (ICP-MS); doğal kaynak suyu, içme suyu, deniz suyu ve atık su numunelerinde çok düşük konsantrasyonlarda $\left(\mu \mathrm{g} \mathrm{L}^{-1}, \mathrm{ng}\right.$ $\mathrm{L}^{-1}$ ) dahi elementlerin çoklu tayinlerine imkân veren gelişmiş bir analitik tekniktir. Bu teknikte çözelti halindeki numune, taşıyıcı gaz (argon) ile iyonlaştırma ünitesine (plazma) gönderilir ve bu bölgede yüksek sıcaklıklarda ( 10000 Kelvin) iyonlaşan elementler, kütle/yük (m/z) oranına göre bir kütle spektrometresi (MS) ünitesinde tayin edilirler (Montaser, 1998). Bir ICP-MS cihazının temel bileşenleri Şekil 1'de gösterilmiştir.
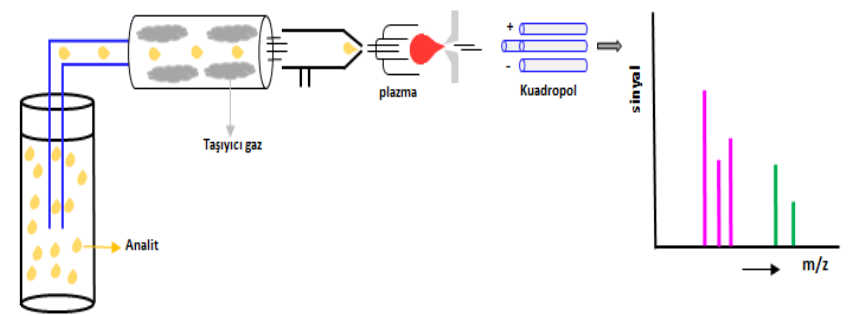

Şekil 1. ICP-MS çalışma prensibi akım şeması.

Figure 1. Schematic illustration of the ICP-MS working princible.

Su örneklerinde geçiş metallerinin yanı sıra lantanit ve aktinit sınıfı elementlerinin hassas şekilde tayin edilebilmesi, buna ek olarak elementlerin izotop miktarının ölçülebilmesine olanak sağlaması gibi özellikler ICP-MS tekniğinin en önemli avantajları arasında yer almaktadır (Dressler vd., 2007; Maxwell III \& Jones, 2009).

Bu çalışmada, Giresun ili şehir merkezinde bulunan bazı araç yıkama merkezlerinde araçların temizlenmesiyle çevreye salınan atık su örneklerindeki $\mathrm{Cd}, \mathrm{As}, \mathrm{Pb}$, Ni ve $\mathrm{Cr}$ gibi ağır metallerin miktarları ICP-MS kullanılarak tayin edilmiştir. Araç yıkama merkezlerinde kullanılan suyun potansiyel olarak atık su kabul edilebileceği ve bu sulardaki ağır metal konsantrasyonlarının kirlilik düzeyi hakkında bilgi sağlayacak olması bu çalışmanın dikkat çeken özelliğidir.

\section{MATERYAL VE METOT}

Kimyasallar ve kullanılan cihazlar: Ölçüm kaplarının temizlenmesi ve metal standart çözeltilerinin hazırlanması için kullanılan ultra saf su Direct-Q 8UV (18,2 m $\Omega$, Milli-Q, Millipore-Merck, Darmstadt, Germany) cihazından temin edilmiştir. Kalibrasyon çözeltileri için gerekli olan $\mathrm{Cd}$, As ve Cr elemetleri High-Purity Standards (Charleston, SC, USA $10 \mathrm{mgL}^{-1}$ ); $\mathrm{Pb}$ ve $\mathrm{Ni}$ elemetlerinin standart çözeltileri ise Millipore Sigma (Darmstadt, Germany, $1000 \mathrm{mgL}^{-1}$ ) firmalarından temin edilmiştir. Atık su örneklerini toplamak için gerekli numune kaplarını, olası bir kirlilikten arındırmak ve su numenelerini asitlendirmek için gerekli nitrik asit $\left(\mathrm{HNO}_{3}\right)$, Merck $(65 \%$, ultrapure reagent, Darmstadt, Germany) firmasından temin edilmiştir. Numunelerin süzme işlemleri için vakum süzme düzeneği (Merck, Darmstadt, Germany) kullanılmıştır. Ölçüm basamağına hazır hale getirilen atık su numunelerinin ağır metal içeriği ise Agilent 7700 model ICP-MS (Santa Clara, CA 95051 United States) cihazi ile belirlenmiştir.

Atık su örneklerin toplanması ve ölçüm basamă̆ı: $\mathrm{Bu}$ çalışma için gerekli atık su numuneleri, Giresun ilinde yedi farklı oto yıkama merkezinden toplanmıştır. Örnek toplama işlemi için önceden nitrik asitle temizlenmiş 500 $\mathrm{mL}$ hacminde polietilen numune kapları kullanılmıştır. Atık sular, oto yıkama merkezlerinin akar kısımlarından her bir istasyon için üç tekrar olacak şekilde (21 adet) toplanmıştır. Atık su örneklerinin toplandığ bölgeler P1, P2, P3, P4, P5, P6 ve P7 olarak etiketlenip Şekil 2'de gösterilmiştir.

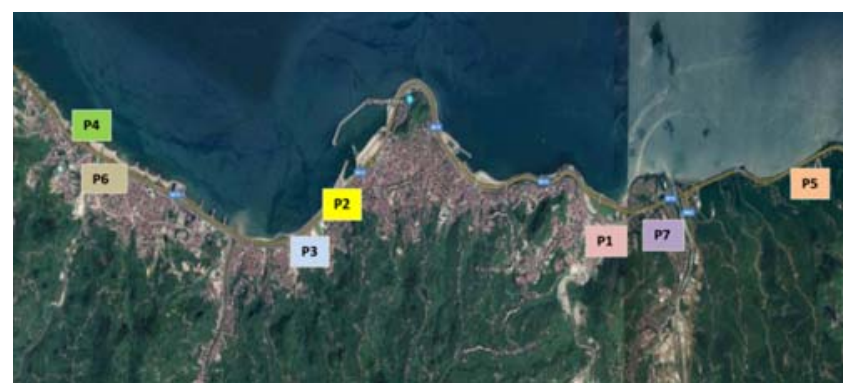

Şekil 2. Atık su örneklerinin toplandığı istasyonlar, Giresun, Türkiye.

Figure 2. The stations for collected waste water samples, Giresun, Turkey.

Tüm atık su örnekleri aynı gün içinde Giresun Üniversitesi Merkezi Araştırma Laboratuvarına getirilerek 0,45 $\mu \mathrm{m}$ gözenekli selüloz membran filtreler (Agilent Technology, Germany) kullanılarak ayrı ayrı süzülmüştür. Herhangi bir metal çökmesini engellemek amacı ile süzülen örnekler, nitrik asit konsantrasyonu $0,1 \mathrm{~mol} \mathrm{~L}^{-1}$ olacak şekilde asitlendirilmiş ve ağır metal içerikleri ICP-MS cihazı ile tayin edilmiştir. Atık su numunelerinin tayin akım şeması Şekil 3'de gösterilmiştir.

ICP-MS'in ölçüm öncesi kalibrasyonu için gerekli çözünürlük, kütle kalibrasyonu ve hassasiyet verilerinin 
optimizasyonu için $10 \mu \mathrm{g} \mathrm{L}^{-1}$ lityum (Li), kobalt (Co) itriyum (Y), seryum (Ce) ve talyum (TI) içeren tuning çözeltisi (Agilent, katalog no:5184-3556) kullanılmıştır. Cihazda okside olmuş iyon kalibrasyonu $\mathrm{CeO}^{+} / \mathrm{Ce}^{+}(\% 1,1-1,4)$ oranı kullanılarak yapılmıştır. ICP-MS cihazı için gerekli diğer çalışma parametreleri Tablo 1'de gösterilmiştir.

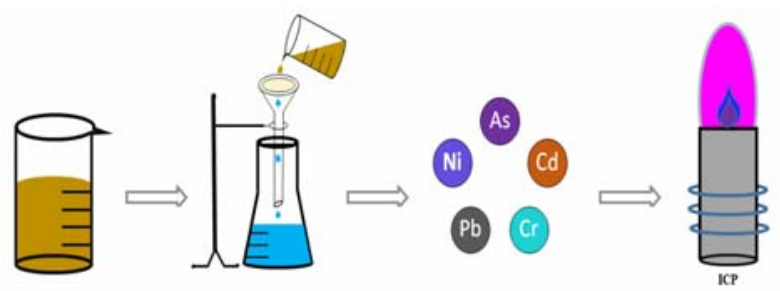

Şekil 3. Atık su numunelerinin ICP-MS ile tayin şeması.

Figure 3. The determination scheme of waste water samples with ICP-MS.

Tablo 1. Agilent 7700 ICP-MS çalışma parametreleri

Table 1. The operating parameters of Agilent 7700 ICP-MS.

\begin{tabular}{ll}
\hline Parametre & Değeri, Birimi \\
\hline RF güç & $1600 \mathrm{Watt}(\mathrm{W})$ \\
Çarpışma gazı & Helyum $(\mathrm{He}), 5,0 \mathrm{~mL} / \mathrm{min}$ \\
Plazma gaz akışı & Argon $(\mathrm{Ar}), 18,0 \mathrm{~L} / \mathrm{min}$ \\
Nebulizatör pompası & $0,1 \mathrm{rps}$ \\
Nebulizatör gaz akış1 & $0,98 \mathrm{~L} / \mathrm{min}$ \\
Çözünürlük $(\mathrm{m} / \mathrm{z})$ & $244 \mathrm{amu}$ \\
Omega lens & $9,4 \mathrm{~V}$ \\
Omega ön gerilim & $-80 \mathrm{~V}$ \\
Enerji ayırımı & $5,0 \mathrm{~V}$ \\
OctP RF & $200 \mathrm{~V}$ \\
\hline
\end{tabular}

\section{BULGULAR}

Atık su numunelerinde tayini yapılacak olan elementleri içeren kalibrasyon çözeltileri hazırlanmış ve veriler Tablo 2'de gösterilmiştir. Numune içerisindeki her bir elementin konsantrasyonu, elde edilen kalibrasyon verilerine göre hesaplanmış ve sonuçlar Tablo 3'de gösterilmiştir.

Tablo 2. Atık su örneklerinde tayini yapılan elementlere ait kalibrasyon doğrusu verileri.

Table 2. The calibration curve data for the determined elements in waste water samples.

\begin{tabular}{|c|c|c|c|}
\hline Element & $\begin{array}{c}\text { Kalibrasyon aralığ } \\
\left(\mu \mathrm{g} \mathrm{L}^{-1}\right)\end{array}$ & Kalibrasyon denklemi & $\begin{array}{c}\text { Regrasyon Katsayısı } \\
\left(\mathbf{R}^{2}\right)\end{array}$ \\
\hline $\mathbf{C d}$ & $1-500$ & $y=2791,1 x+8187,5$ & 0,9998 \\
\hline As & $1-500$ & $y=12051 x+43101$ & 0,9997 \\
\hline $\mathbf{P b}$ & $1-500$ & $y=26693 x+127642$ & 0,9999 \\
\hline $\mathbf{N i}$ & $1-500$ & $y=108,04 x+4858,4$ & 0,9947 \\
\hline $\mathrm{Cr}$ & $1-500$ & $y=9061,9 x+30786$ & 0,9998 \\
\hline
\end{tabular}

Ölçümlerin doğruluğu (validasyon) numune matriksine ekleme/geri kazanım (tayini yapılmak istenilen analitin bilinen konsantrasyonunun, numune ortamına ilave edilerek ölçülmesi) yöntemiyle belirlenmiştir. Her bir element için elde edilen ekleme/geri kazanım değerleri Tablo 3'de gösterilmiştir.

Tablo 3. ICP-MS ile atık su numunelerinde tayin edilen ağır metal konsantrasyonları ve ekleme/geri kazanım değerleri

Table 3. Heavy metal concentrations and addition/recovery values determined in waste water samples with ICP-MS.

\begin{tabular}{|c|c|c|c|c|c|c|c|c|}
\hline \multicolumn{9}{|c|}{ İstasyonlar } \\
\hline & Element & P1 & P2 & P3 & P4 & P5 & P6 & P7 \\
\hline \multirow{4}{*}{ Cd } & Numunede tayin edilen $(\mu \mathrm{gL}-1)$ & TSA & TSA & TSA & TSA & TSA & TSA & TSA \\
\hline & Eklenen $(\mu \mathrm{gL}-1)$ & 10 & 10 & 10 & 10 & 10 & 10 & 10 \\
\hline & Bulunan $(\mu \mathrm{gL}-1)$ & $9,1 \pm 0,5$ & $9.1 \pm 0,5$ & $8,9 \pm 0,6$ & $9,4 \pm 0,4$ & $9,5 \pm 0,6$ & $9,2 \pm 0,4$ & $9,5 \pm 0,5$ \\
\hline & $\%$ Geri kazanım & $91 \pm 4$ & $91 \pm 5$ & $89 \pm 4$ & $94 \pm 4$ & $95 \pm 4$ & $92 \pm 3$ & $95 \pm 3$ \\
\hline \multirow{4}{*}{ As } & Numunede tayin edilen ( $\mu$ gL-1) & $3,8 \pm 0,1$ & $8,7 \pm 0,2$ & 2,6 & $5,6 \pm 0,3$ & $11,9 \pm 0,1$ & $1,0 \pm 0,1$ & $15,2 \pm 0,3$ \\
\hline & Eklenen $(\mu \mathrm{gL}-1)$ & 10 & 10 & 10 & 10 & 10 & 10 & 10 \\
\hline & Bulunan ( $\mu \mathrm{gL}-1)$ & $14 \pm 0,5$ & $19 \pm 0,5$ & $13 \pm 0,4$ & $15 \pm 0,5$ & $22 \pm 0,8$ & $10,9 \pm 0,4$ & $24 \pm 0,9$ \\
\hline & $\%$ Geri kazanım & $102 \pm 5$ & $103 \pm 5$ & $104 \pm 4$ & $94 \pm 3$ & $101 \pm 6$ & $99 \pm 4$ & $88 \pm 4$ \\
\hline \multirow{4}{*}{$\mathbf{P b}$} & Numunede tayin edilen ( $\mu$ gL-1) & $13,7 \pm 0,2$ & $26,9 \pm 0,4$ & $2,8 \pm 0,2$ & $15,5 \pm 0,4$ & $4,8 \pm 0,1$ & $6,7 \pm 0,1$ & $4,8 \pm 0,1$ \\
\hline & Eklenen $(\mu \mathrm{gL}-1)$ & 10 & 10 & 10 & 10 & 10 & 10 & 10 \\
\hline & Bulunan ( $\mu \mathrm{gL}-1)$ & $24 \pm 2$ & $36 \pm 2$ & $13 \pm 1$ & $26 \pm 1$ & $14 \pm 1$ & $16 \pm 1$ & $14 \pm 1$ \\
\hline & $\%$ Geri kazanım & $103 \pm 4$ & $91 \pm 3$ & $96 \pm 3$ & $105 \pm 4$ & $92 \pm 3$ & $93 \pm 4$ & $92 \pm 4$ \\
\hline \multirow{4}{*}{$\mathbf{N i}$} & Numunede tayin edilen $(\mu \mathrm{gL}-1)$ & $4,7 \pm 0,8$ & $31,5 \pm 1,1$ & $2,9 \pm 0,1$ & $16,3 \pm 0,8$ & $4,6 \pm 0,2$ & $16,2 \pm 0,7$ & $4,7 \pm 0,1$ \\
\hline & Eklenen $(\mu \mathrm{gL}-1)$ & 10 & 10 & 10 & 10 & 10 & 10 & 10 \\
\hline & Bulunan $(\mu \mathrm{gL}-1)$ & $14 \pm 1$ & $42 \pm 2$ & $12 \pm 1$ & $26 \pm 1$ & $15 \pm 1$ & $27 \pm 1$ & $14 \pm 1$ \\
\hline & $\%$ Geri kazanım & $93 \pm 4$ & $105 \pm 6$ & $91 \pm 4$ & $97 \pm 3$ & $104 \pm 3$ & $108 \pm 3$ & $93 \pm 4$ \\
\hline \multirow{4}{*}{$\mathrm{Cr}$} & Numunede tayin edilen $(\mu \mathrm{gL}-1)$ & $1,7 \pm 0,2$ & $9,8 \pm 0,4$ & $1,2 \pm 0,1$ & $8,2 \pm 1,1$ & $3,4 \pm 0,2$ & $2,7 \pm 0,2$ & N.D \\
\hline & Eklenen $(\mu \mathrm{gL}-1)$ & 10 & 10 & 10 & 10 & 10 & 10 & 10 \\
\hline & Bulunan ( $\mu \mathrm{gL}-1)$ & $12 \pm 1$ & $20 \pm 1$ & $11 \pm 1$ & $17 \pm 1$ & $13 \pm 1$ & $12 \pm 1$ & $9 \pm 1$ \\
\hline & $\%$ Geri kazanım & $103 \pm 6$ & $102 \pm 4$ & $98 \pm 5$ & $88 \pm 4$ & $96 \pm 4$ & $93 \pm 3$ & $90 \pm 3$ \\
\hline
\end{tabular}

Tablo 3'de elde edilen verilerden yola çıkarak arsenik, kurşun, nikel ve krom konsantrasyonlarının, istasyonlara göre farkl1lık gösterip göstermediği tek yönlü anova testi (IBM SPSS statistics, 12 version, SPSS Inc., USA) ile incelenmiştir. Analizi yapılan tüm metallerin normal dağılım gösterdiği (Kolmogorov-Smirnov K-S test) ve buna bağlı olarak da arsenik ve krom konsantrasyonlarının istasyonlara göre farklılık gösterdiği $(\mathrm{P}<0,05)$ gözlemlenmiştir. Kurşun miktarının P5 ve P7 istasyonlarında, nikelin ise P1, P5 ve P7 istasyonlarında farkl1lık göstermediği gözlemlenmiştir.

\section{TARTIŞMA VE ÖNERILER}

Endüstriyel faaliyetler sonucu doğaya salınan ağır metallerin insan ve çevre sağlığı için ciddi sorunlar oluşturduğu bilinen bir gerçektir. Özellikle endüstri bölgelerinde çevreye salınan ağır metal içerikli atık suların, 
göl ve içme suyu kaynaklarını kirletmesi önemli çevre sorunlarından biridir. Bu açıdan atık sularda ağır metal konsantrasyonlarının belirlenmesi, içme, nehir ve göl sularının kirlenme derecesinin tespiti ve gerekli tedbirlerin alınması açısından büyük önem arz etmektedir. Benzer şekilde oto yıkama merkezlerinde kullanılan suların çevreye salındığı bilinmekte ve bu atık suların muhtemel olarak bazı ağır metalleri de içerebileceği ön görülmektedir. $\mathrm{Bu}$ amaçla, Giresun ilinde bulunan farklı oto yıkama merkezlerinden toplanan atık suların içeriğindeki bazı ağır metaller ICP-MS tekniği ile belirlenmiştir.

Kadmiyum, özellikle çinko-kadmiyum pillerinde kullanılan, çok düşük konsantrasyonlarda dahi insan ve hayvan dokularında birikerek toksik özellik gösteren bir ağır metaldir. Tütün ürünleri potansiyel kadmiyum kaynağ 1 olarak bilinmektedir (Nazari, 2009). Bu çalışmada, ICPMS ile analizi yapılan atık su numunelerinde kadmiyum tespit edilememiştir. Araç yıkama atık su örneklerinde bu metale rastlanılmaması kadmiyumun kullanım alanlarıyla açılanabilir.

Arsenik, deri ve ahşap korucuyu (bakır ve krom arsenat) olarak kullanılan, Amerikan Çevre Koruma Örgütü (EPA) tarafindan birinci sınıf toksik ve Uluslararası Kanser Araştırmaları Ajansı (IARC) tarafindan ise kanserojen madde sınıfinda yer alan ağır metaldir (Assis vd., 2019, Gedik vd., 2019). Atık su analizi yapılan her istasyonda arsenik metaline rastlanmıştır. Arsenik, tarım alanında böcek öldürücü ve herbisit olarak kullanılır. Ayrıca alaşım ve madencilik faaliyetlerinde sıklıkla kullanılması nedeniyle atık su numunelerinde bulunma olasılı̆̆ı yüksek bir metaldir (Gürkan, 2015).

Kurșun, kemiklere nüfuz edebilen ve kolayca beyin hücrelerine taşınıp sinir sitemini tahrip etme özelliğine sahip toksik bir ağır metaldir. Araç yıkama merkezlerinin atık su içeriklerinde kurşun tespit edilmesi bu metalin araç bataryaları, petrol ürünleri ve boya sanayisinde kullanılmasıyla açıklanabilir (Mansel vd., 2019).

Nikel, solunum sistemi rahatsızlıklarına yol açan alerjik ve toksik bir metaldir. Analiz edilen tüm istasyonlarda nikel metaline rastlanmıştır. Nikel özellikle elektro kaplama ve akümülatörlerde kullanılan bir metaldir (Karve \& Rajgor, 2009), bu açıdan oto yıkama atık sularına karışma ihtimali yüksektir.

Krom, deri tabaklama, metalurji ve isıya dayanıklı malzemelerde kullanılması nedeniyle yüzey sularına karışabilen toksik metaller arasındadır. Çok düşük konsantrasyonlarda Cr (III) insan sağlığı için gerekli iken Cr (VI) toksik özellik gösterir (Almeida vd., 2019). Atık su analiz sonuçlarında P7 istasyonunda krom metaline rastlanmazken, diğer istasyonlarda düşük konsantrasyonlarda krom tespit edilmiştir. Krom metalinin araç yıkama atık sularında gözlemlenmesi özellikle bu metalin galvanik kaplama endüstrisinde kullanılması ile açıklanabilir.

Mevcut çevre politikaları, su ekosistemlerindeki toksik madde seviyelerini azaltmayı ve uygun atık su arıtılmasından sonra suyun tekrar kullanılmasını teşvik etmeyi amaçlar. Böylece endüstriyel faliyetler sonucu doğaya salınan metallerin konsantrasyonlarının tespiti ve su ile olan etkileşimlerinin azaltılması su kaynaklarının korunması açısından son derece önemlidir. Ağır metallerin atık sulardan uzaklaştırılması için kimyasal çökeltme, iyon değişimi ve membran filtrasyonu gibi klasik yöntemler kullanılmaktadır. Bunun yanında etkinliği yüksek farklı arındırma teknikleri de kullanılabilir. Örnek olarak, atık sulardan $\mathrm{Cr}, \mathrm{Ni}, \mathrm{Zn}, \mathrm{Cu}$ ve $\mathrm{Cd}$ metallerinin uzaklaştırılması için zeloit (Álvarez-Ayuso vd., 2003); Cd, Co, Pb metallerinin uzaklaştırılması için aktif karbon (Mikuła \& Puzio, 2007) etkin şekilde kullanılmıştır. Bunlara ek olarak atık su numunelerinden $\mathrm{Pb}, \mathrm{Ni}, \mathrm{Cr}, \mathrm{V}$ elementlerinin uzaklaştırılması için doğal kaynaklı adsorban olarak solucan gübresi (Vermicompost) (Urdaneta vd., 2008), çok düşük konsantrasyonlarda arsenik metalinin uzaklaştırılması için ise biyomateryal olarak su sümbülü bitkisi (Eichhornia crassipes) (Al Rmalli vd., 2005) kullanılmıştır. Yapılan bu çalışmalar ışığında gerek araç yıkama merkezleri gerekse diğer endüstriyel fabrika atık sularının çevreye salındığı bölgelerde yüksek adsorblama özelliğine sahip materyaller filtre olarak kullanılıp, ağır metallerin çevreye salınımları önlenebilir. Böylece metallerin geri kazanımları da sağlanarak çevre ve insan sağlı̆̆ı üzerindeki zararlı etkileri azaltılabilir.

\section{SONUÇ}

$\mathrm{Bu}$ çalışmada elde edilen verilerden, atık su örneklerinde krom metali düşük konsantrasyonlarda tespit edilmişken (istasyon $\mathrm{P} 7$ 'de $\mathrm{Cr}$ tespit edilmemiştir) kadmiyum metaline rastlanmamıştır. Ayrıca tüm istasyon verilerinde arsenik, kurşun ve nikel metalleri farklı konsantrasyonlarda tespit edilmiştir. Ağır metal içeriğine sahip atık suların, içme ve kullanım sularını kirleterek insan sağlığını olumsuz yönde etkileyeceği açıktır. Bu sonuçlardan da yola çıkarak analizi yapılan atık sularda toksik özelliğe sahip metallerin belirlenmesi atık su yönetiminin ne denli önemli olduğunu ortaya koymaktadır.

\section{TEŞEKKÜR}

$\mathrm{Bu}$ çalışma Giresun Üniversitesi Bilimsel Araştırma Projeleri Birimi (Proje no: 300318-90, Giresun, Türkiye) tarafından desteklenmiştir. ICP-MS ölçümleri sırasında gösterdikleri destek için Gümüşhane Üniversitesi Merkezi Araştırma Laboratuvarı yönetimi ve öğretim görevlisi kadrosuna teşekkürlerimi sunarım. 


\section{KAYNAKLAR}

Akieh, M.N., Lahtinen, M., Väisänen, A. \& Sillanpää, M. (2008). Preparation and characterization of sodium iron titanate ion exchanger and its application in heavy metal removal from waste waters. Journal of Hazardous Materials, 152, 640-647.

Al Rmalli, S.W., Harrington, C.F., Ayub, M. \& Haris, P.I. (2005). A biomaterial based approach for arsenic removal from water. Journal of Environmental Monitoring, 7, 279-282.

Almeida, J.C., Cardoso, C.E.D., Tavares, D.S., Freitas, R., Trindade, T., Vale, C. \& Pereira, E. (2019). Chromium removal from contaminated waters using nanomaterials - A review. Trends in Analytical Chemistry, 118, 277-291.

Álvarez-Ayuso, E., García-Sánchez, A. \& Qquerol, X. (2003). Purification of metal electroplating waste waters using zeolites. Water Research, 37, 48554862 .

Assis, R.C., Faria, B.A.A., Caldeira, C.L., Mageste, A.B., de Lemos, L.R. \& Rodriguesa, G.D. (2019). Extraction of arsenic(III) in aqueous twophase systems: A new methodology for determination and speciation analysis of inorganic arsenic. Microchemical Journal, 147, 429-436.

Dressler, V.L., Pozebon, D., Matusch, A. \& Becker, J.S. (2007). Micronebulization for trace analysis of lanthanides in small biological specimens by ICPMS. International Journal of Mass Spectrometry, 266, 25-33.

Duffus, J.H. (2002). "Heavy Metals"-A meaningless term? Pure and Applied Chemistry, 74, 93-807.

Duruibe, J.O., Ogwuegbu, M.O.C. \& Egwurugwu, J.N. (2007). Heavy metal pollution and human biotoxic effects. International Journal of Physical Sciences, 2, 112-118.

Gedik, K., Kongchum, M. \& Delaune R.D. (2019). Arsenic Uptake and Depuration by Red Swamp Crayfish, Procambarus clarkii. Journal of Anatolian Environmental and Animal Sciences, 3, 332-337.

Grant, R.L. \& Grant, E. (1987). Grant and Hackh's Chemical Dictionary,5th ed.,McGraw-Hill, New York, 657p.

Gürkan, R., Kır, U. \& Altunay, N. (2015). Development of a simple, sensitive and inexpensive ion-pairing cloud point extraction approach for the determination of trace inorganic arsenic species in spring water, beverage and rice samples by UVVis spectrophotometry. Food Chemistry, 180, 3241.
Jahromi, E.Z., Bidari, A., Assadi, Y., Hosseini, M.R.M. \& Jamali, M.R. (2007). Dispersive liquid-liquid microextraction combined with graphite furnace atomic absorption spectrometry Ultra trace determination of cadmium in water samples. Analytica Chimica Acta, 585, 305-311.

Karve, M. \& Rajgor, R.V. (2009). Octadecyl bonded silica membrane disk modified with Cyanex302 for separation and flame atomic absorption spectrometric determination of nickel from tap water and industrial effluent. Journal of Hazardous Materials, 166, 576-580.

Khajeh, M., Sarafraz-Yazdi, A. \& Moghadam, A.F. (2017). Modeling of solid-phase tea waste extraction for the removal of manganese and cobalt from water samples by using PSO-artificial neural network and response surface methodology. Arabian Journal of Chemistry, 10, 1663-1673.

Mansel, C., Fross, S., Rose, J., Dema, E., Mann, A., Hart, H., Klawinski, P. \& Vohra, B.P.S. (2019). Lead exposure reduces survival, neuronal determination, and differentiation of P19 stem cells. Neurotoxicology and Teratology, 72, 8-70.

Maxwell III, S.L. \& Jones, V.D. (2009). Rapid determination of actinides in urine by inductively coupled plasma mass spectrometry and alpha spectrometry: A hybrid approach. Talanta, 80, 143-150.

Mikuła, B. \& Puzio, B. (2007). Determination of trace metals by ICP-OES in plant materials after preconcentration of 1,10-phenanthroline complexes on activated carbon. Talanta, 71, 136140.

Montaser, A. (1998). Inductively Coupled Plasma Mass Spectrometry, 1rd ed., Wiley-VCH, USA, 1004p.

Nazari, S. (2009). Liquid phase microextraction and ultratrace determination of cadmium bymodified graphite furnace atomic absorption spectrometry. Journal of Hazardous Materials, 165, 200-205.

Urdaneta, C., Parra, L.M.M., Matute, S., Garaboto, M.A., Barros, H. \& Vázquezde, C. (2008). Evaluation of vermicompost as bioadsorbent substrate of $\mathrm{Pb}, \mathrm{Ni}, \mathrm{V}$ and $\mathrm{Cr}$ for waste waters remediation using Total Reflection X-ray Fluorescence. Spectrochimica Acta Part B: Atomic Spectroscopy, 63, 1455-1460.

Vinodh, R., Padmavathi, R. \& Sangeetha, D. (2011). Separation of heavy metals from water samples using anion exchange polymers by adsorption process. Desalination, 267, 267-276. 